\title{
Hydrothermal solidification of green tuff / tobermorite composites
}

\author{
Midori TAKAGI, Hirotaka MAEDA ${ }^{\dagger}$ and Emile Hideki ISHIDA \\ Graduate School of Environmental Studies, Tohoku University, 6-6-20, Aramaki-Aza-Aoba, Aoba-ku, Sendai 980-8579
}

\begin{abstract}
Mesoporous green tuff / tobermorite composites were synthesized by hydrothermal treatment of powder compacts consisting of waste green tuff and slaked lime. XRD results showed that chlorite, the mineral responsible for the green coloration of green tuff, remained after hydrothermal treatment. Tobermorite formed as a result of a reaction between the quartz inherent in green tuff and slaked lime. The formation of tobermorite led to an increase in bending strength, reaching $12 \mathrm{MPa}$ after $10 \mathrm{~h}$ of hydrothermal treatment, as well as to an increase in specific surface area and mesopore volume. The composite adsorbed a greater quantity of water vapour and ammonia gas than waste green tuff.
\end{abstract}

(C)2009 The Ceramic Society of Japan. All rights reserved.

Key-words : Green tuff, Tobermorite, Hydrothermal solidification, Composite, Mesoporous material

[Received August 18, 2009; Accepted October 15, 2009]

\section{Introduction}

Green tuff is known for its beautiful pale green colour and has been used as interior wall tiles in buildings. A large proportion of the green tuff that is mined every year ends up as waste stones or powder during the process of being quarried and cut into tiles. Hinai town, Akita, for example is one of the principal places where green tuff is mined in Japan, and over 60 percent of the green tuff mined there is destined to landfill. Waste green tuff stones and powder have been reported to adsorb odorous particles ${ }^{1)}$ and have therefore been used as deodorizers in the local chicken farms of Hinai town. Novel ways of recycling these wastes are being sought after. The solidification of green tuff powder would broaden its application to cover areas such as architecture, where it would provide a cheap and aesthetically pleasing ingredient for building materials. Sintering at high temperatures, however, would not be an ideal way of solidifying green tuff powder, as it has been reported that chlorite, the mineral responsible for the green coloration of green tuff, decomposes at $873 \mathrm{~K}^{2}{ }^{2)}$

The formation of calcium silicate hydrate products such as C$\mathrm{S}-\mathrm{H}$ gel and tobermorite in materials solidified hydrothermally from $\mathrm{CaO}-\mathrm{SiO}_{2}-\mathrm{H}_{2} \mathrm{O}$ systems has been suggested to induce strength in these materials. ${ }^{3)-5)}$ Therefore, an alternative method of solidifying green tuff would be to create a composite of green tuff and tobermorite using hydrothermal synthesis. As green tuff is abundant in quartz, the synthesis of tobermorite could be achieved by mixing it with slaked lime and treating the mixture hydrothermally. Hydrothermal synthesis proceeds at relatively low temperatures of $423-473 \mathrm{~K}$ and would be an effective method of solidifying green tuff powder, as the chlorite present in it would not decompose at these temperatures.

Furthermore, the formation of tobermorite has been suggested to generate mesopores of $10 \mathrm{~nm}$ diameter. Some mesoporous materials such as Wakkanai diatomaceous shale ${ }^{6)}$ have been found to adsorb water vapour by the principle of capillary condensation and are used as ingredients in commercially available,

Corresponding author: H. Maeda; E-mail: hirotaka.maeda@mail. kankyo.tohoku.ac.jp humidity-controlling building materials. If a mesoporous composite consisting of green tuff and tobermorite could be synthesized, it may result not only in the solidification of green tuff, but also in the creation of a novel building material possessing the ability to improve indoor environments by adsorbing water vapour and other gases. In this research, solidification of green tuff powder was attempted using hydrothermal synthesis, and the adsorption of water vapour and ammonia gas by the solidified samples were evaluated.

\section{Experimental procedures}

Waste green tuff powder with particle size less than $75 \mu \mathrm{m}$, obtained from Nakano Sangyo Co., Ltd., and slaked lime were used as starting materials for the synthesis of the green tuff / tobermorite composite. The green tuff powder was analysed by powder X-ray diffractometry and was found to consist of albite, quartz and chlorite as well as three different zeolites: stilbite, laumontite and faujasite. Slaked lime was prepared by adding distilled water to quicklime, the latter of which was prepared by calcining calcium carbonate, obtained from Wako Pure Chemical Industries, Ltd., at $1000^{\circ} \mathrm{C}$ for $3 \mathrm{~h}$. The green tuff and slaked lime powders were grinded and mixed together in a porcelain mortar such that their $\mathrm{Ca} / \mathrm{Si}$ ratios were $0.2,0.4$ and 0.8 . The $\mathrm{Ca} / \mathrm{Si}$ ratio was kept below 1 so that the colour of raw green tuff could be reflected in the solidified product as much as possible. After adding $10 \mathrm{mass} \%$ of distilled water to the powder mixture, $5.0 \mathrm{~g}$ of the mixture were pressed in a rectangular steel die with a uniaxial compaction pressure of $10 \mathrm{MPa}$. The tile-shaped powder compacts, measuring $40 \mathrm{~mm}$ long, $15 \mathrm{~mm}$ wide and $5 \mathrm{~mm}$ thick, were then placed inside an autoclave vessel with $10 \mathrm{ml}$ of distilled water and treated hydrothermally at $180^{\circ} \mathrm{C}$ for $10 \mathrm{~h}$. After hydrothermal treatment, the samples were dried overnight at $80^{\circ} \mathrm{C}$. Another sample consisting only of green tuff powder was made for comparison using the same procedures.

The bending strength of the samples was measured using the three-point bending test (EZ Graph, Shimadzu Co.). For each varying period of hydrothermal treatment, the average and standard deviation of three bending strengths were taken. The mineralogical phases in the samples were identified by powder X-ray diffraction analysis (RINT-2200VL, Rigaku Co., $40 \mathrm{kV}, 40 \mathrm{~mA}$ ) 
using $\mathrm{Cu} \mathrm{K} \alpha$ radiation. The relative quantities of the mineral phases in the samples were measured, semi-quantitatively, using the internal standard method. Alumina was used as the internal standard. The peak integrals of quartz (011), portlandite (001), tobermorite (002) and alumina (113) were measured across $2 \theta$ ranges of $26.3^{\circ}-27.0^{\circ}, 17.5^{\circ}-18.4^{\circ}, 7^{\circ}-8^{\circ}$ and $43^{\circ}-43.7^{\circ}$, respectively. The morphology of the fracture surface of the samples was observed under a scanning electron microscope ( $\mathrm{S}-$ 4100, Hitachi, Ltd.). The pore size distribution and total pore volume of the samples were measured using mercury intrusion porosimetry (PoreMaster 33, Quantachrome Instruments). The specific surface area and mesopore volume of the samples were measured using nitrogen gas sorption analysis (AUTOSORB-1, Quantachrome Instruments) after pre-heating at $80^{\circ} \mathrm{C}$ in vacuum. Water vapour adsorption isotherms were obtained for the samples using water vapour sorption analysis (Hydrosorb 1000, Quantachrome Instruments) after pre-heating at $80^{\circ} \mathrm{C}$ in vacuum. To examine the ammonia gas adsorption properties of the samples, the concentration of ammonia gas adsorbed on the samples was monitored.

\section{Results and discussion}

The colour of the samples appeared to become more pale with increasing $\mathrm{Ca} / \mathrm{Si}$ ratio. It was thus apparent that a low $\mathrm{Ca} / \mathrm{Si}$ ratio was desirable in synthesising a composite resembling the colour of raw green tuff as much as possible. Figure 1 shows the mean bending strengths of the samples and their standard deviations. The data point at $\mathrm{Ca} / \mathrm{Si}$ ratio 0.033 shows the bending strength of the sample consisting of green tuff powder alone. It was evident that green tuff powder could not be solidified by hydrothermal treatment without the addition of slaked lime. Among the three other samples, the sample with $\mathrm{Ca} / \mathrm{Si}$ ratio 0.4 showed the highest bending strength. Therefore, samples treated hydrothermally for $0-10 \mathrm{~h}$ with $\mathrm{Ca} / \mathrm{Si}$ ratio 0.4 were used for the following analyses.

Figure 2 shows the mean bending strengths of the samples before and after hydrothermal treatment, and their standard deviations. The strength of the sample increased steadily with time and, after $10 \mathrm{~h}$ of hydrothermal treatment, reached a value of $12 \mathrm{MPa}$.

Figure 3 shows the XRD patterns of the samples before and after hydrothermal treatment. The XRD pattern of the sample before hydrothermal treatment showed peaks corresponding to

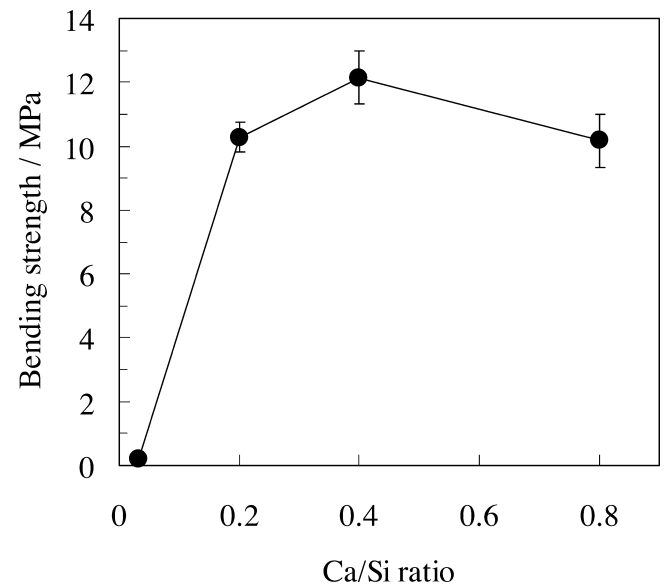

Fig. 1. Bending strengths of the samples prepared with different $\mathrm{Ca} / \mathrm{Si}$ ratios. the mineral phases in green tuff: albite, quartz, chlorite, stilbite, laumontite and faujasite, as well as those corresponding to portlandite and alumina, the internal standard. From the XRD patterns of the hydrothermally treated samples, it was observed that the intensities of the peaks corresponding to quartz and portlandite decreased with increasing curing time. On the other hand, a new peak identified as tobermorite appeared after $4 \mathrm{~h}$. No significant changes were seen in the quantities of the remaining phases. The fact that there was no significant change in the quantity of chlorite shows that hydrothermal synthesis was indeed effective in solidifying green tuff powder without compromising its green colour. In order to investigate the quantities of each mineral phase in the samples against curing time, the ratios of the peak area of each phase against that of alumina were measured using the internal standard method. Figure 4 shows these ratios plotted against curing time for quartz, portlandite and tobermorite. The ratios corresponding to quartz and portlandite decreased with increasing curing time and, the ratio corresponding to tobermorite increased. These results suggest that a reaction between quartz and portlandite led to the formation of

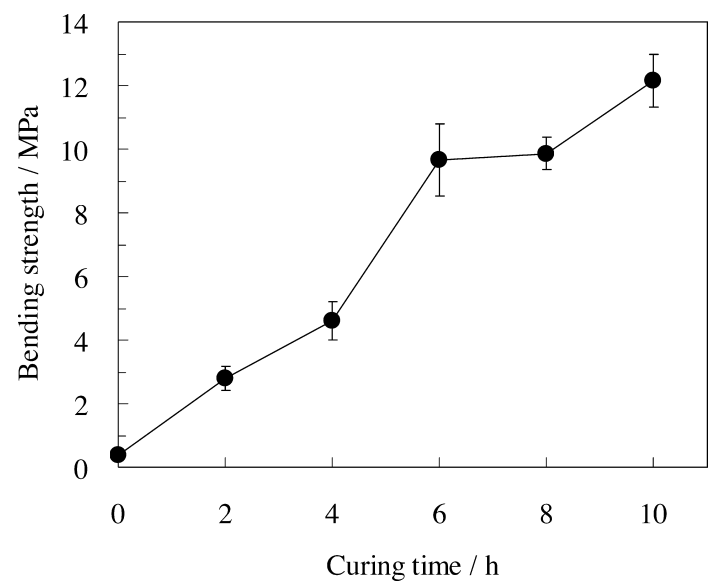

Fig. 2. Bending strengths of the samples cured for different curing times.

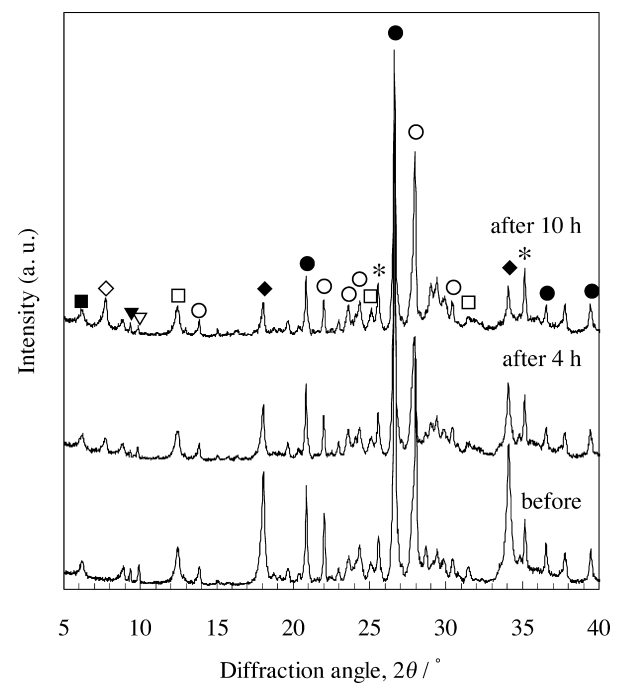

Fig. 3. XRD patterns of the samples cured for different curing times. $\bigcirc:$ Albite, ๑: Quartz, $\square$ : Chlorite, $\nabla$ : Stilbite, $\mathbf{\nabla}$ : Laumontite, $\mathbf{\square}$ : Faujasite, $\diamond$ : Portlandite, $\diamond$ : Tobermorite, $*$ : Alumina. 

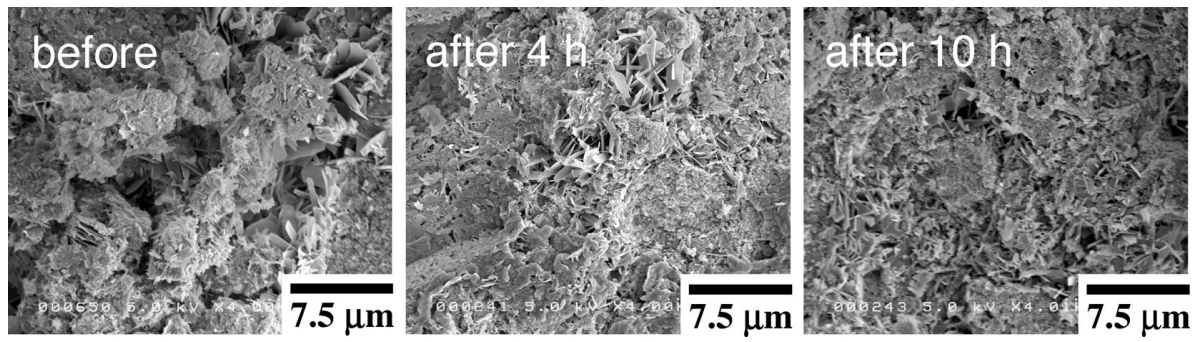

Fig. 5. SEM micrographs of the fracture surface of the samples cured for different curing times.

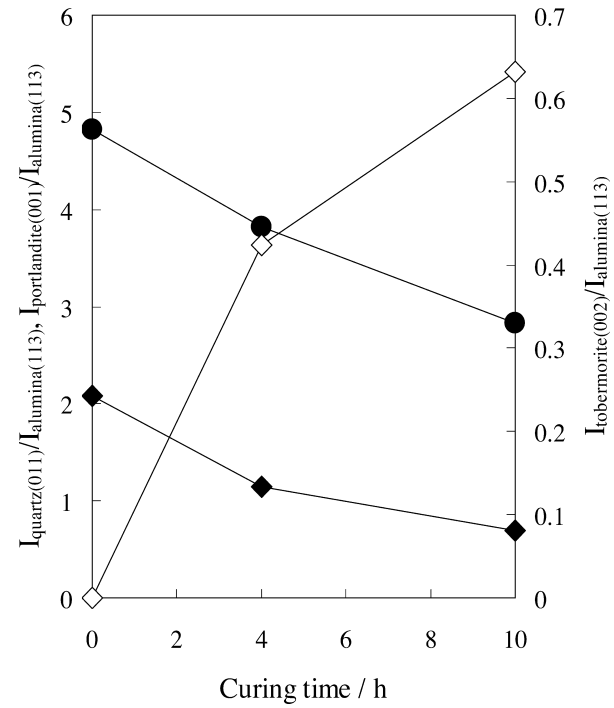

Fig. 4. Plot of $\mathrm{I}_{\text {quartz(}(011)} / \mathrm{I}_{\text {alumina(113), }}$, $\mathrm{I}_{\text {portlandite(001) }} / \mathrm{I}_{\text {alumina(113) }}$ and $\mathrm{I}_{\text {tobermorite(002) }}$ $/ \mathrm{I}_{\text {alumina(113) }}$ against curing time, where $\mathrm{I}_{\text {phase }}$ denotes the integrated peak area of each phase. ๑: Quartz, $\diamond$ : Portlandite, $\diamond$ : Tobermorite.

tobermorite.

Figure 5 shows the SEM micrographs of the samples before and after hydrothermal treatment. Before hydrothermal synthesis, particles of green tuff were observed along with platy, hexagonal crystals resembling those of slaked lime. Voids were seen between the ingredient particles. After $4 \mathrm{~h}$ and $10 \mathrm{~h}$, the interparticle voids observed at $0 \mathrm{~h}$ were filled with platy crystals measuring approximately $2-3 \mu \mathrm{m}$ long, identified as tobermorite from the XRD results of Fig. 2. The tobermorite crystals were intertwined with each other, creating pores in between.

Figure 6 shows the pore size distribution curves and total pore volumes of the samples before and after hydrothermal treatment. The pore size distribution curve of the untreated sample has two broad peaks: one at $0.7 \mu \mathrm{m}$ and another at $80 \mathrm{~nm}$. The former is attributed to spaces between the green tuff particles, and the latter is likely attributed to spaces between the green tuff and slaked lime particles. After $4 \mathrm{~h}$, these peaks became smaller and a new peak appeared at $10 \mathrm{~nm}$. From the XRD pattern and SEM micrograph at $4 \mathrm{~h}$, this new peak can be attributed to pores formed between the intertwining crystals of tobermorite. After $10 \mathrm{~h}$, the peak corresponding to the interparticle pores shifted to finer diameters, and the peak corresponding to the pores between the intertwining crystals of tobermorite grew larger. Meanwhile, the total pore volume of the sample remained practically constant, indicating that its strength development did not depend upon it.

Table 1 shows the specific surface area and mesopore volume of green tuff and the sample cured for $10 \mathrm{~h}$. The formation of

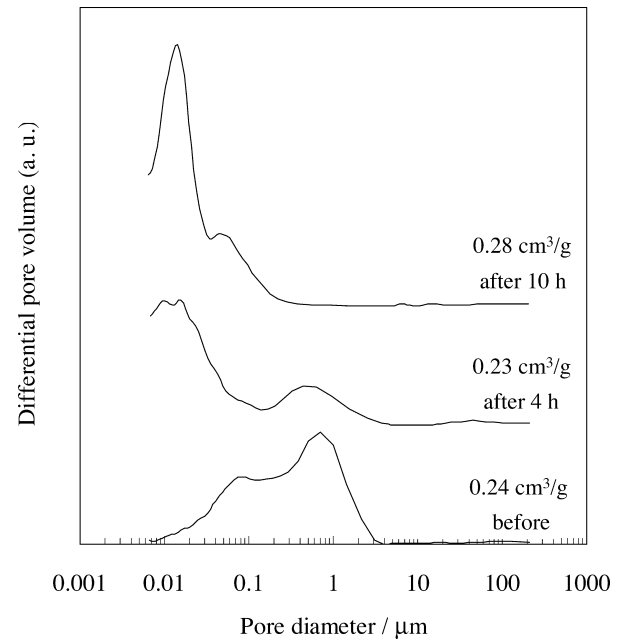

Fig. 6. Pore size distribution curves and total pore volumes of the samples cured for different curing times.

Table 1. Specific Surface Area and Mesopore Volume of Green Tuff and the Sample Cured for $10 \mathrm{~h}$

\begin{tabular}{lcc}
\hline \multicolumn{1}{c}{ Sample } & $\begin{array}{c}\text { Specific surface area } \\
\left(\mathrm{m}^{2} / \mathrm{g}\right)\end{array}$ & $\begin{array}{c}\text { Mesopore volume } \\
\left(\mathrm{cm}^{3} / \mathrm{g}\right)\end{array}$ \\
\hline Green tuff & 5 & 0.008 \\
Sample cured for $10 \mathrm{~h}$ & 33 & 0.06 \\
\hline
\end{tabular}

tobermorite within the composite resulted in a material possessing a much greater specific surface area and mesopore volume in comparison to raw green tuff.

As a result of the reaction between quartz and slaked lime, tobermorite formed after $4 \mathrm{~h}$ and increased thereafter. The formation of tobermorite crystals within the interparticle voids of the powder-compact led to the filling of, and consequently to the reduction of these voids, inducing strength within the material. The intertwining structure of the tobermorite crystals led also to the formation of mesopores, which in turn caused an increase in specific surface area.

Figure 7 shows the water vapour adsorption isotherms of green tuff and the composite synthesized from $10 \mathrm{~h}$ of hydrothermal treatment. The quantities of water adsorbed by green tuff and the composite were $13 \mathrm{~cm}^{3} / \mathrm{g}$ and $110 \mathrm{~cm}^{3} / \mathrm{g}$, respectively. The composite adsorbed over eight times more water than was adsorbed by green tuff. The composite had a much greater volume of mesopores compared to green tuff and, this is likely to have contributed to its greater adsorption of water by causing capillary condensation. The isotherm of the composite showed a wide hysteresis loop characteristic of mesoporous materials, 


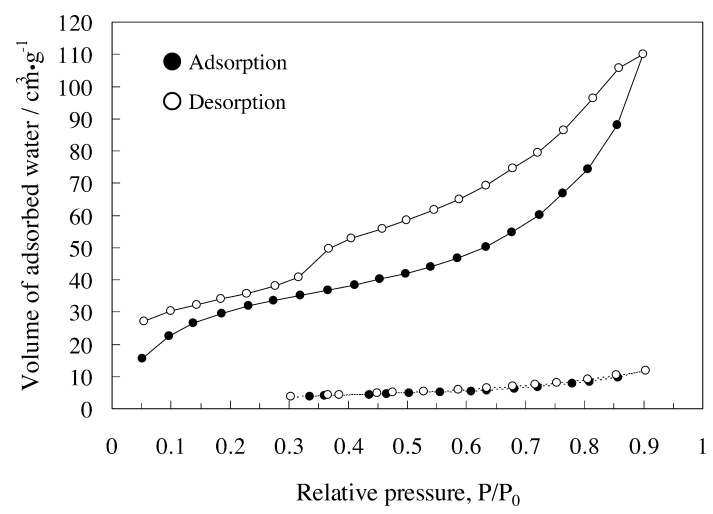

Fig. 7. Water vapour adsorption isotherms of green tuff and the sample cured for $10 \mathrm{~h}$. ------ Green tuff, — Sample cured for $10 \mathrm{~h}$.

whilst that of green tuff hardly showed any.

As a result of the ammonia adsorption test using $370 \mathrm{ppm}$ as the initial concentration of ammonia gas, the composite adsorbed $140 \mathrm{ppm}$ of ammonia gas, while green tuff adsorbed only $100 \mathrm{ppm}$. The large specific area of the composite, greater than that of green tuff, is likely to be one of the factors contributing to its greater adsorption of ammonia gas. On the other hand, preliminary adsorption tests conducted beforehand have shown that tobermorite adsorbs more ammonia gas per unit area than green tuff: in one test using $375 \mathrm{ppm}$ as the initial concentration of ammonia gas, tobermorite adsorbed $79 \mathrm{ppm} / \mathrm{m}^{2}$ of ammonia gas while green tuff adsorbed only $65 \mathrm{ppm} / \mathrm{m}^{2}$. It is therefore also possible that the material characteristic of tobermorite had contributed to the greater adsorption performance of the composite.

\section{Conclusion}

Green tuff / tobermorite composites with numerous mesopores were synthesized hydrothermally from waste green tuff powder and slaked lime. Tobermorite formed as a result of a reaction between the quartz inherent in green tuff and slaked lime. The formation of tobermorite led to an increase in the strength of the material, as well as to the creation of a mesoporous material capable of adsorbing more water vapour and ammonia gas than raw green tuff. Chlorite remained after hydrothermal treatment and the colour of green tuff was therefore reflected in the composite. The composite could potentially be used as a novel building material possessing strength, aesthetic beauty and the ability to improve indoor environments by controlling humidity and adsorbing unwanted gases.

Acknowledgements The present work was supported in part by Grants-in-Aid for Scientific Research from the Japan Society for the Promotion of Science and TOSTEM Foundation for Construction Materials Industry Promotion.

\section{References}

1) Y. Sugai, K. Sasaki, S. Takahata and H. Naka, Journal of Japan Institute of Aggregate Technology, 37, 153-161 (2005).

2) K. Tomita, S. Iwashita, M. Yamamoto and N. Oba, Reports of the Faculty of Science, Kagoshima University... Earth sciences and biology, 11, 105-120 (1978).

3) Z. Zing, F. Jin, T. Hashida, N. Yamasaki and E. H. Ishida, $J$. Mater. Sci., 43, 2356-2361 (2008)

4) H. Maeda, T. Okada and E. H. Ishida, J. Ceram. Soc. Japan, 44, 147-151 (2009)

5) H. Maeda, S. Kato and E. H. Ishida, J. Appl. Ceram. Technol., 6, 431-436 (2009).

6) S. Suzuki, S. Tomura and M. Maeda, Proc. Int. Conf. Ecomaterials, 1999, 511-514 (1999). 